\title{
Umbilical endometriosis in a 39 years old parous woman: A Case Report
}

\author{
Ashraf $\mathrm{F}^{1}$, Yasmin $\mathrm{N}^{2}$, Islam JA ${ }^{3}$, Choudhury $\mathrm{FR}^{4}$, Guha $\mathrm{K}^{5}$
}

\begin{abstract}
Endometriosis is a common gynaecological condition and presents mainly with involvement of the pelvic organs. However umbilical endometriosis is uncommon. A correct differential diagnosis can be difficult and the use of epiluminescence and MRI is suggested for the accuracy of preoperative diagnosis. This case report was experienced at a tertiary care hospital at Dhaka city. The patient was 39 years old multigravid woman presented with umbilical swelling and pain during menstruation for last 1year with cyclical bleeding from the umbilical region for last 4 months. The patient had regular menstrual bleeding since the time of menarche. The patient had no previous history of endometriosis, dysmenorrhea or dyspareunia. Physical examination showed a hyperpigmented tender paraumbilical swelling with bloody discharge through umbilicus. An accurate anamnesis and clinical examination together with the use of high resolution ultrasonography and fine needle aspiration cytology led to an accurate pre-operative diagnosis of umbilical endometriosis. The surgical approach to umbilical endometriosis represented an important step in achieving a satisfying result. The lesion to be excised and adequate umbilical repositioning was done. The patient was asymptomatic at the follow-up visit (12 months after surgery), however, nevertheless warned of the risk of recurrence. A natural-looking umbilicus was observed in cases with minimal visible scars.
\end{abstract}

Keywords: Endometriosis, umbilicus, extra pelvic endometriosis, menstruating tumor

\section{Introduction}

Presence of functioning endometrial tissue in sites other than uterine mucosa is called endometriosis. It was first reported in 1860 by Von Recklinghausen ${ }^{1}$. Commonly it develops at a fertile age with more incidences in women at an age between 30 and 40 years old o $^{2,3}$. The common location is within the pelvis. However, extrapelvic endometriosis is a fairly uncommon disorder and difficult to diagnosis. The various sites are bladder, kidneys, ureters, bowel, omentum, liver, lungs, diaphragm, abdominal wall and extremities ${ }^{4-6}$.

Umbilical endometriosis has been reported in more than one hundred cases and represents the location of $0.5-1 \%$ of ectopical endometrioses ${ }^{7}$. Its clinical manifestation often consists of a dome-shaped, brown nodule, with intermittent pain and bleeding from the umbilicus during the menstrual period. The umbilical nodule may be due to umbilical granuloma, simple inclusion cyst, umbilical hernia, benign or malignant neoplasm of the umbilicus. Umbilical discharge or weeping should be a different condition of pilonidal sinus, urachal cyst, urachal sinus rare cause is umbilical endometriosis which may be the differential diagnosis for umbilical nodule with discharge and some authors propose the use of epiluminescence microscopy (ELM) and magnetic resonance imaging (MRI) for the accuracy of preoperative diagnosis ${ }^{8-11}$.

In this case report umbilical endometriosis was described which was found in a tertiary care hospital at Dhaka and was diagnosed accurately and was treated accordingly.

\section{Case presentation}

A 39-year-old parous woman presented with symptoms of pain \& swelling in and around the umbilicus during menstruation for one year and spontaneous and periodic bleeding from the umbilicus for four months. The pain

1. Prof. Fatema Ashraf, Professor, Department of Gynaecology \& Obstetrics, Shaheed Suhrawardy Medical College, Dhaka

2. Dr. Nilofar Yasmin, Junior Consultant, Department of Gynaecology \& Obstetrics, Shaheed Suhrawardy Medical College, Dhaka

3. Dr. Jinnat Ara Islam, Assistant Professor, Department of Gynaecology \& Obstetrics, Shaheed Suhrawardy Medical College, Dhaka

4. Dr. Farzana Rabee Choudhury, Junior Consultant, Department of Gynaecology \& Obstetrics, Shaheed Suhrawardy Medical College, Dhaka

5. Dr. Kaberi Guha, Junior Consultant, Department of Gynaecology \& Obstetrics, Shaheed Suhrawardy Medical College, Dhaka

\section{Correspondence}

Dr. Nilofar Yasmin, Junior Consultant, Department of Gynaecology \& Obstetrics, Shaheed Suhrawardy Medical College, Dhaka, Bangladesh E-mail:nilofar71@gmail.com; Cell no.: +8801819147556 
was started two days before menstruation and continue for the entire duration of the period. For the last four months it was accompanied by bleeding trackling from the umbilical area after one or two days of starting menstruation. The patient had regular, normal and painless menstrual periods and did not wish for any treatment for such. The patient had an history of one caesarean sections delivery six years back. The patient was not taking any form of hormonal contraception and only used barrier method. Clinical examination visit revealed that the patient had a $4 \times 4 \mathrm{~cm}$ firm nodule at and around the umbilicus with slightly more on right side of umbilicus which was appeared to be a reddish brown colour with wooden consistency and had a foul smelling brownish discharge from the umbilicus. Suspecting that the patient had got an infection and the patient was swabbed with antiseptics and given a five-day course of oral broadspectrum antibiotics.

The patient was come one months later for check up and was found that there was no infection but no improvement of other symptoms. The patient was then underwent an high resolution ultrasound scan that revealed a $15-\mathrm{mm}$ thin-walled hypoechoic nodular mass in right paraumbilical region which was approximately $10 \mathrm{~mm}$ below the skin surface corresponded to the umbilical endometriosis. The FNAC from the swelling revealed the diagnosis of umbilical endometriosis. The key clinical feature that led to the correct diagnostic hypothesis of umbilical endometriosis was the temporal association of the bleeding, pain and swelling with the menstrual period. The patient was admitted and was offered for both medical and surgical management. The patient was adopted to have danazol tablet. The severity of pain and swelling decreased; however, was continued to persist in spite of danazol. Then the patient was advised for surgical excision. The patient was successfully underwent excision of the nodule with accompanying umbilical reconstruction.

Histology was confirmed the diagnosis of endometriosis and was revealed the presence of multiple foci of endometrium composed of glandular and stromal elements. No epithelial atypical cell was seen and the excision appeared complete. The patient was seen 12 months after the surgery and found to be asymptomatic with a normal umbilicus.
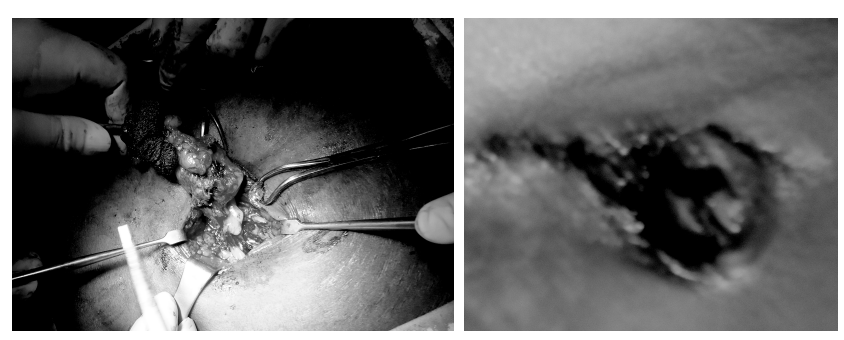

Fig: Excision of Umbilical endometriosis

\section{Discussion}

Endometriosis is a typical benign pathology of women of a fertile age, with the highest incidence in women between 30 and 40 years. It can be distinguished an internal endometriosis in which ectopic cells are located in the myometrial tissue which was called adenomyosis and an external or ectopic one with pelvic (most common) or extra-pelvic localization known as extragenital ${ }^{12}$.

A number of theories have been put forward to explain its development. According to Sampson ${ }^{13}$, it is due to the reflux of menstrual blood and the implantation of endometrial cells into the peritoneal surface of the pelvic organs. Based on this theory, it is difficult to explain the rare occurrence of endometriosis in the breast, lung or umbilicus ${ }^{14}$. Other observers believe that endometriosis develops from pluripotent cells of the coelom. This theory explains the development of endometriosis wherever coelomic epithelium or vestige occurs in the pelvis, umbilicus and hernial sacs. Furthermore, embolization by lymphatic vessels has been suggested. No single theory can explain the spontaneous occurrence of endometriosis in all affected sites ${ }^{15}$.

Umbilical endometriosis is rare with an estimated incidence of $0.5-1.0 \%$ of all cases of endometrial ectopia ${ }^{16,17}$. It may appear during active menstrual life as a small, firm, bluishpink mass of the umbilical area, with a diameter varying from a few millimeters to $6 \mathrm{~cm}$. The endometrioma may cause pain, swelling or tenderness mainly in the premenstrual period, as this endometrial tissue responds cyclically but not consistently, to the ovarian hormones. Sometimes secretion or some bleeding may occur through the umbilicus, concomitant with menstruation; for this reason, it is often called the menstruating tumor. On examination, tender indurated umbilici, which exude old blood on pressure, is pathognomic. Umbilical endometriosis frequently exists as a solitary lesion without accompanying pelvic disease ${ }^{18}$. This patient also did not have associated pelvic endometriosis. Preoperative diagnosis is difficult to make and sometimes the diagnosis is made after excision only.

This case was diagnose clinically before operation and confirmed after histopathology. The differential diagnosis of an umbilical lesion includes hernia, primary and metastatic neoplasms, embryological residual mass and various granulomas like pyogenic, foreign body. Various diagnostic methods have been described in the literature. Nowadays, ultrasonography can be carried out at high definition, increasing its accuracy in the diagnosis of various pathologies. In the observed cases of umbilical endometriosis, recurrent findings were the presence of a hyperechogenic structure with small hypoechogenic spots inside, a predominant venous pattern, and the absence of connections to the deep fascial plane. The spontaneous dominant venous flow is a characteristic of benign 
tumors ${ }^{19}$. The absence of continuity with the deep fascial plane allows its differential diagnosis from invasive malignancies and hernias ${ }^{20}$. Based on the experience, it was believe that the combination of the typical clinical manifestation, in particular the symptoms worsening during the premenstrual period, together with the aforementioned echographic findings strongly points to a diagnosis of umbilical endometriosis. Therefore, the uses of more expensive and accurate examinations like MRI, are not required and should be confined to atypical and uncertain cases of umbilical masses.

Another important point in the management of umbilical endometriosis is the surgical approach. Medical treatment with the use of progesterone, oral contraceptive pill, and danazol is not effective and gives only partial relief in symptoms. However, this type of medication has undesirable androgenic side-effects like amenorrhea, hirsutism, weigh gain, as well as acne which may influence compliance. Gonadotrophin agonist has been usad leading to prompt improvement in symptoms with no change in the lesion $\operatorname{size}^{21}$. During surgical treatment umbilical repositioning is mandatory and the surgeon should aim for the removal of such benign lesions with minimal visible scars and a natural-looking result. In this cases a hemicircumferential incision in the inner aspect of the umbilical opening was performed ${ }^{22,23}$. This allowed adequate access for the lesion to be excised with an adequate umbilical repositioning. During this procedure, it is important to obtain an inverted umbilicus and to use, when required, internal absorbable sutures between the umbilical dermis and the abdominal rectus fascia to guarantee umbilical inversion. This patient needs to be followed up because of the chance of recurrence.

\section{Conclusion}

One should have a high index of suspicion of umbilical endometriosis when a women presents with a painful swelling in the umbilicus and bleeding from it during menstruation. This condition can be confused with other surgical condition. Efforts should be made to make a preoperative diagnosis with the help of imaging techniques and FNAC. Medical treatment is not helpful. Wide excision with umbilical repositioning with a minimal visible scar is mandatory to obtain a natural looking umbilicus and a satisfactory result.

\section{References}

1. Markham SM, Carpenter SE, Rock JA. Extrapelvic endometriosis. Obstet Gynecol Clin North Am 1989;16:193-219
2. Attaran M, Falcone T, Goldberg J. Endometriosis still tough to diagnose and treat. Cleve Clin J Med 2002; 69: 647-50

3. Caligaris PH, Masselot R, Ducassou MJ, Le Treut Y, Bricot R. Endometriose de la paroi abdominale. J Gynecol Obstet Biol Reprod 1981;10: 465-471

4. Joly D, Harden H, Huguet C. Endometriose de la paroi abdominale dans les suites a long terme d'une çesarienne. Lyon Chir 1988;84: 106-108

5. Baldi A, Campioni M, Signorile PG. Endometriosis: Pathogenesis, diagnosis, therapy and association with cancer. Oncol Rep 2008;19(4): 843-846

6. Zollner U, Girshcick G, Steck T, Dietl J. Umbilical endometriosis without previous pelvic surgery: a case report. Arch Gynecol Obstet, 2003;267: 258-260

7. Hill AD, Banwell PE, Sangwan Y, Darzi A, Manzies-Gown N. Endometriosis and umbilical swelling. Clin Exp Obst Gyn , 1994;21: 28-29

8. Farace F, Gallo A, Rubino C, Manca A, Campus GV. Endometriosis in a trocar tract: is it really a rare condition? A case report. Minerva Chir, 2005;60(1): 67-69

9. Harvey E: Umbilical endometriosis. Acta Obstet Gynecol Scand, 1976;112: 1435-1436

10. De Giorgi V, Massi D, Mannone F, Stante M, Carli P. Cutaneous endometriosis: Non-invasive analysis by epiluminescence microscopy. Exp Dermatol, 2003;28: 315-317

11. Hartigan CM, Holloway BJ. MR imaging features of endometriosis at umbilicus. Br J Radiol, 2005; 78: 755-757

12. Yu CY, Perez-Reyes M, Brown JJ, Borrello JA. MR appearance of umbilical endometriosis. J Comput Assist Tomogr, 1994;18: 269-271

13. Onesti MG, Cigna E, Buccheri EM, Alfano C. Endometriosi ombelicale primaria. Dermatologia Clinica, 2005; 2:75-78

14. Sampson JA. Development of implantation theory for origin of peritoneal endometriosis. Am J Obstet Gynec, 1940;40: 549-557

15. Beirne MF, Berkheiser SW. Umbilical endometriosis. A case report. Am J Obstet Gynec, 1955; 69: 895-897

16. Ayala YR, Mota GM. Endometriosis: physiopathology and investigation trends (first part). Ginecol Obstet Mex 2007;75:477-483

17. Rubegni P, Sbano P, Santopietro R, Fimiani M. Case 4. Umbilical endometriosis. Clin Exp Dermatol ,2003;28(5): 571-572

18. Michowitz M, Baratz M, Stavorovsky M. Endometriosis of the umbilicus. Dermatologica, 1983;167:326-330

19. Ozkol M, Yoleri L, Demir MA, Demireli P, Pabuscu Y. The significance of venous dominance in color Doppler ultrasound for the diagnosis of primary nodular skin lesions: a new perspective in classification. Clin Imaging , 2006;30:43-47

20. Srivastava A, Hughes BR, Hughes LE, Woodcock JP. Doppler ultrasound as an adjunct to the differential diagnosis of pigmented skin lesions. Br J Surg; 1986;73(10):790-792

21. Iovino F, Ruggiero R, Irlandese E, Gili E, Loschiavo F. Umbilical endometriosis associated with umbilical hernia. Management of a rare occurrence. Chir Ital 2007;59(6): 895-899

22. Chene G, Darcha C, Dechelotte P, Mage G, Canis M. Malignant degeneration of perineal endometriosis in episiotomy scar, case report and review of the literature. Inter J Gynecol Cancer 2007;17:709-714

23. Heaps JM, Nieberg RK, Berek JS. Malignant neoplasms arising in endometriosis. Obstet Gynecol, 1990;75(6):1023 